\title{
STUDENT LEADERSHIP TRAINING AS A STRESS REDUCTION STRATEGY AT A SOUTH AFRICAN UNIVERSITY
}

\author{
C. N. Mulenga* \\ Organisational Psychology, School of Management Studies \\ e-mail: chao.mulenga@uct.ac.za
}

\author{
K. Brouze* \\ Organisational Psychology, School of Management Studies \\ e-mail: Kim@krunch.co.za
}

\section{S. Gardner-Lubbe*}

Department of Statistics

e-mail: sugnet.lubbe@uct.ac.za

*University of Cape Town

Cape Town, South Africa

\section{ABSTRACT}

Student leadership at universities are an integral part of both leadership and skills development for the students. The appointment of student leaders in different roles such as tutors, residence assistants and other research assistant roles have become a standard feature of student engagement with universities. The objective of this study was to examine the relationship between role overload, role stress and role satisfaction and investigates whether training has an effect on role satisfaction for residence student leaders at a South African university. The appointment of residence assistance has generated a lot of interest due to the emotional and physical demands of this role. A descriptive design using a cross-sectional survey was administered to the total population of student leaders at a local university, 101 males and 82 females responded to the survey. The gender composition was 30.4 per cent males, 22.8 per cent female and 46.7 were mixed gender residences. Findings showed that role overload and role stress were negatively correlated to role satisfaction; whereas training was perceived positively in relation to role satisfaction. These results emphasize the importance of maintaining acceptable levels of role stress and role satisfaction and reinforced previous findings that reported training as a means to achieving role satisfaction for student leaders. This study showed that providing satisfactory training was effective in increasing skills and reducing role overload and role stress and increasing role satisfaction for the student leaders.

Key words: role stress, role overload, student leadership, training satisfaction, role satisfaction 


\section{INTRODUCTION}

There has been an increase in interest in student leadership in institutions of higher learning which has led to different leadership development initiatives being implemented. Appointment of residence leadership has become an integral aspect of tertiary institutions (Kezar 2000, 55). Institutions use different models of leadership development, including but not limited to the appointment of Resident Assistants (RAs). RAs are defined as a support structure for other students (Powers 2003, 3). For the purposes of this study an RA will be referred to as a student leader (SL) because the population under investigation included leaders who did not receive remuneration for their roles.

The role of a student leader is reported to be demanding and stressful, and generates negative outcomes with regards to student academic performance (Dodge 1990, 40). These negative outcomes relating to leadership roles have resulted in a debate which questions the appointment of student leaders in tertiary institutions (Onoffrietti 2000, 17).

\section{OVERVIEW}

For tertiary institutions, the benefits of appointing student leaders include: 1) students are able to identify more strongly with, and feel more comfortable approaching, a fellow student; 2) student leaders are best placed to identify and solve the problems of other students appropriately as a peer; 3) having student leaders in authority may attract students to live on campus and engage in leadership roles, leading to the development of a more civically involved student body; and 4) student leaders are less costly employees than full-time staff (Casey 2009, 11).

Student leadership roles in residences include that of a mediator, a facilitator, a counsellor, an advisor, a student and a cheerleader (Casey 2009, 12). In these roles, SLs are expected to create a learning and living environment which facilitates academic learning and social support, as well as personal and social growth. In addition to the role expectations of student leadership, student leaders are expected to honour their academic commitments and responsibilities as well as social needs. The self-reported mean time spent by student leaders in this role was 15 hours a week (Powers 2003, 6). The competing demands create an environment in which student leaders have been left feeling overloaded and stressed. A previous study reported that SLs feel more role strain and role overload, leading to reduced academic performance, when they are involved in multiple leadership activities (Powers 2003, 8). Increased stress levels for student leaders have been reported as an outcome of possessing inadequate resources and competencies to deal with the evolving demands that the leadership roles pose for them (Powers 2003, 8). 
According to Dodge (1990, 41), the complicated and difficult demands, such as dealing with HIV/Aids, date rape, alcoholism and eating disorders, that a student leader attends to create a stressful work experience. The manifestation of role stress for student leaders has become an issue central to their academic and social wellbeing, due to the fact that these factors can lead to various physiological and behavioural issues, and attitudinal outcomes such as role dissatisfaction and stress (Casey 2009, 3).

\section{Objective}

The objective of this study was to determine whether or not the student leader training has an effect on the role stress by examining role overload, leadership training and role satisfaction. Stress is commonly viewed within three main paradigms: 1 ) as a stimulus; 2) as a response; and 3) as an interaction (Buunk, De Jonge, Ybema and De Wolff 1998, 146). This study investigated student leaders' stress from an interaction approach, where stress was defined as the interaction between the environment and the person. In the interaction approach, situations are only stressful depending on whether the individual appraises it as threatening to his or her resources (Buunk et al. 1998, 147).

\section{HYPOTHESIS DEVELOPMENT}

Role overload (RO) has been reported as an important antecedent of role stress (Gilboa, Shimon, Fried and Cooper 2008, 227). Two categories of role overload are identified: quantitative and qualitative role overload Quantitative role overload is defined as not having enough time to fulfil job expectations; whereas qualitative role overload is defined as not having adequate competencies to fulfil demands or to meet the expected quality of performance. The occurrence of both qualitative and quantitative role overload is based on an individual's perception and not on objective reality. A proposed reason for the subjective nature of role overload is lack of self-evaluation objectivity by individuals. In a study of salespeople in, Jaramillo, Mulki and Boles (2011, 339) reported positive correlation between quantitative role overload and role stress. Studies conducted have so far focused on quantitative overload, neglecting the role of qualitative role overload.

The Demands and Ability Fit (D-AF) Model (French, Caplan and Harrison 1982) indicates that individuals will experience increased role stress when there is a greater discrepancy between their skills, knowledge, education and abilities, and their required job competencies. To gain clarity on the relationship between role overload and role stress, this study investigated qualitative and quantitative role overload as sources of role stress. 
Student leaders who are stressed have reported feeling unsatisfied with and apathetic about their university and its policies, hence lowering their level of performance, and thus creating an unpleasant living environment for students whom they are required to support (Onoffrietti 2000, 48). Job satisfaction has continuously presented itself as an important outcome of role stress (Casey 2009, 14). This leads to SL's ignoring breaches of residence policies by students whom they are overseeing and, in extreme cases, the RAs themselves breaking the rules (Casey 2009, 16). Although this has led to some institutions eliminating the student leadership system (Dodge 1990, 40), there are benefits to having student leaders in tertiary institutions.

- Hypothesis 1: Role stress is positively related to quantitative role overload.

- Hypothesis 2: Role stress is positively related to qualitative role overload.

The relationship between role overload and role stress (RST) is important due to its association with behavioural, attitudinal and physiological outcomes (Robbins, Judge, Odendaal and Roodt 2009, 65). Reported behavioural outcomes include smoking, drug abuse and suicide intentions. Physiological outcomes include backache, high blood pressure, muscle tension, headaches, hypertension and cardiovascular disease. Attitudinal outcomes include low role satisfaction, life satisfaction, organisational citizenship behaviour, commitment and motivation, and high turnover intentions (Robbins et al. 2009, 77). Job satisfaction has continuously presented itself as a key outcome of role stress as it is related to a variety of other significant variables such as organisational commitment, motivation, turnover intentions, life satisfaction and job performance.

\section{Role satisfaction}

Job satisfaction is defined as a positive feeling that results from the appraisal of one's job characteristics (Robbins et al. 2009, 73). Studies that investigated the relationship between role stress, role overload and role satisfaction have reported varying results. According to Activation Theory (Janssen 2001, 1049), there is a curvilinear relationship between role overload, role stress and role satisfaction in which only moderate levels of stress benefit role satisfaction, and high or low levels are detrimental to it. In this study the term 'role satisfaction' (RSA) was used instead of 'job satisfaction', because a portion of the sample consisted of unpaid student leaders.

- Hypothesis 3: Role stress is negatively related to role satisfaction.

- Hypothesis 4: Quantitative role overload is negatively related to role satisfaction. 
- Hypothesis 5: Qualitative role overload is negatively related to role satisfaction.

Training enables individuals to achieve the level of knowledge, skill and competence needed to carry out their work effectively. Schmidt $(2007,490)$ reported a significant positive relationship between the amount of training an individual receives and role satisfaction. Schmidt $(2007,491)$ further reported a positive relationship between training satisfaction (TS) and overall role satisfaction. Role overload and stress are reported to be associated negatively with job satisfaction; and since training has been reported to increase job satisfaction, this study proposed that training will be positively related to role satisfaction.

- Hypothesis 6: Training is negatively related to role stress.

- $\quad$ Hypothesis 7: Training is negatively related to quantitative role overload.

- Hypothesis 8: Training is negatively related to qualitative role overload.

- Hypothesis 9: Training is positively related to role satisfaction.

\section{Demographic variables}

Research has shown that demographic factors can affect work overload, job satisfaction and stress. Previous studies have linked demographic variables, such as experience, to stress and performance (Jaramillo et al. 2011, 349). Age was associated with perceptions of stress, job satisfaction and job performance and gender has been reported to affect perceptions of stress. In view of this, gender, age, academic year of study (representing experience) and race were used as control variables.

- Hypothesis 10: Work overload and training will predict role satisfaction when controlling for gender, age, academic year of study and race.

\section{Rationale}

Gaining an understanding of student leaders’ perceptions of the utility of training, role overload, role stress and role satisfaction has been reported to be important for identifying relevant interventions that target issues that are manifested from student leaders' multiple roles (Schmidt 2007, 492). Further research is critical in understanding the relationship between these constructs and the ways in which they affect student stress, which is reported to cause poor academic performance.

Previous studies in this subject have been predominantly in Western countries as reported 
above, with the African experience largely ignored (Curtis 2007, 381). This study provides an opportunity to investigate this subject at a South African tertiary institution. The study set out to answer the question: is there a relationship between student leaders' role overload, training and role stress?

This study is unique for several reasons. The study of role stress has shifted considerably for occupational contexts, let alone that of the student leader in residence. Relationships between constructs are studied using students in leadership positions, a management structure that tertiary institutions are calling upon to develop socially responsible leadership models. This study extends research on student leadership in the local context as well as contributing to global literature on the topic, as no known studies have investigated this phenomenon amongst South African student leaders in residence.

\section{METHOD}

After obtaining ethical clearance from the Commerce Ethics in Research Committee (EiRC), data collection commenced. Students were informed of the confidentiality, anonymity and voluntary participation facets of the study.

Data was collected from 19 residences, where the average number of leaders in each residence was 13 (inclusive of both paid and unpaid student leadership roles). A total of 184 usable responses were received, giving a response rate of 48 per cent. One hundred and one participants were male (54.9\%), 82 were female (44.6\%), and one respondent did not indicate their gender. The gender composition of the surveyed residences was 30.4 per cent male, 22.8 per cent female, and 46.7 per cent mixed gender residence halls. The sample racial composition of student leaders was 69 per cent Black, 15 per cent White, 4 per cent Coloured, 6 per cent Indian, and 0.5 per cent Chinese, with 1.6 per cent of respondents preferring not to answer. The respondents' average age ranged from 18 to $28(M=20.86$; $S D=1.66)$. Of the respondents, 45 per cent were enrolled in their $2^{\text {nd }}$ year of study, 44 per cent in their $3^{\text {rd }}$ year, 15.2 per cent in their $4^{\text {th }}$ year, and 4 per cent in their $5^{\text {th }}$ year.

\section{Measures}

All constructs included in this study were assessed with previously validated scales. A fiveitem training and development scale (Ford and Noe 1987) measuring attitude towards training utility was used to measure training and development. A sample item from the scale is 'My role gives me real opportunities to improve my skills'. Role stress was measured with a six-item scale developed by Paoline III, Lambert and Hogan (2006). A high score (5 = high and $1=$ 
low) on this scale indicated a high level of role stress. A sample item is 'The leadership role often makes me feel tense and uptight'. A composite seven-item scale was used to measure global role satisfaction (Jones, Chonko, Rangarajan and Roberts 2007, 669). Items were adapted to suit the target sample population. A sample item is 'In general I am happy with my leadership role'. The study used two measures for qualitative and quantitative role overload. The first scale had five items to measure quantitative role overload (Jones et al. 2007). A sample item is 'I have to do things I don't have time and energy for'. The second scale used four items for qualitative role overload (Triplett, Mullings and Scarborough 1999, 384). A sample item is 'My roles when dealing with students are sometimes too difficult and/or complex'. All scales used the anchors (1) strongly disagree and (5) strongly agree. Participants were required to provide the following demographic details, which previous studies have reported to be associated with the dependent variable: age, gender, race, and academic year of study.

\section{Results}

An exploratory factor analysis was used to explore the constructs in the data set with the psych package (Revelle 2015) in R (R Core Team 2015). The loadings were estimated with the principal components method, and an Oblimin rotation was applied. A total of 10 of the 29 measures were dropped due to loadings below the cut-off value of 0.55 . Lowering the cut-off value to 0.5 resulted in poor discrimination validity, with AVE values for some latent variables below the square of the mutual correlation. Based on the scree plot (see Figure 1), 5 factors

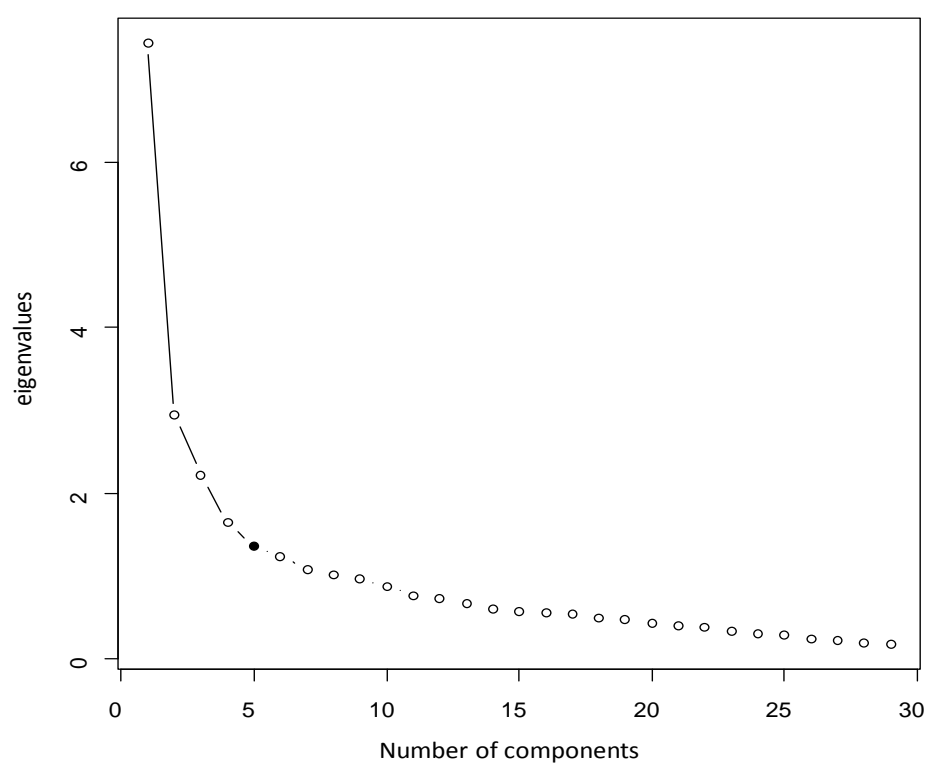

Figure 1: Scree plot 
were initially selected, but it turned out that to obtain satisfactory discrimination validity (AVE larger than squared mutual correlation) all loadings of the fifth factor were below the 0.55 cutoff. The model was refitted with 4 factors and a 0.55 cut-off value. No cross-loadings above 0.4 were detected in the analysis. Each of the 4 latent variables had reliability values between 0.76 and 0.86. Appendix A provides the reliability values, AVE values and ratio of AVE to squared mutual correlation values.

A CFA was used to assess the measurement properties of the 5-scale measurement items in the 4-factor model. The model parameters were estimated using maximum likelihood in $\mathrm{R}$ using the package lavaan (Rosseel 2012). The measurement model results indicated a poor fit to the data $\left(\chi^{2}=286.98\right.$, degrees of freedom 146; root mean square error of approximation 0.074, CI95\% 0.061 and 0.086, comparative fit index 0.886, goodness-of-fit index 0.856 and adjusted goodness-of-fit index 0.813). Poor goodness of fit statistics is not an unusual occurrence as has been reported by Jaramillo et al. (2011) and others.

In order to fit the regression of the latent variables, a full structural equation model was fitted. The modification indices were used to add correlations between error terms as shown in figure 2 , to obtain a satisfactory model fit $\left(\chi^{2}=195.455\right.$, degrees of freedom 142; root mean square error of approximation 0.046, CI95\% 0.029 and 0.062, comparative fit index 0.956, goodness-of-fit index 0.893 and adjusted goodness-of-fit index 0.857$)$. Initially the regression modelled RST as depending on RSA, RO and TD, but RSA did not have a statistically significant dependence with RST. The final model fit obtained resulted in the regression equation

$$
R S T=-0.222 T D+0.586 R O .
$$

Where Role Stress, Training satisfaction and Role Overload represent the standardised latent variable scores. The standard errors of the coefficient estimates were 0.065 and 0.127 for Training satisfaction and Role overload respectively. The model explains 38.8 per cent of the variability in Role stress.

Another model was fitted to allow for the effect of control variables. This model explains 45.5 per cent of the variability in Role stress. However, none of the control variables had a statistically significant effect on Role stress (see Table 1). Again, modification indices were used to add correlations between error terms, to obtain a satisfactory model fit, as shown in Figure $2\left(\chi^{2}=364.092\right.$, degrees of freedom 286; root mean square error of approximation 0.040, CI95\% 0.026 and 0.052, comparative fit index 0.935, goodness-of-fit index 0.867 and adjusted goodness-of-fit index 0.824). 
Table 1: Reliability and validity

\begin{tabular}{|l|c|c|c|c|}
\hline & $\begin{array}{c}\text { Latent variable 1 } \\
\text { (RO) }\end{array}$ & $\begin{array}{c}\text { Latent variable 2 } \\
\text { (RST) }\end{array}$ & $\begin{array}{c}\text { Latent variable 3 } \\
\text { (RSA) }\end{array}$ & $\begin{array}{c}\text { Latent variable 4 } \\
\text { (TS) }\end{array}$ \\
\hline Reliability & 0.836 & 0.835 & 0.761 & 0.773 \\
\hline AVE & 0.427 & 0.510 & 0.544 & 0.465 \\
\hline & $\begin{array}{c}\text { Ratio of AVE of } \\
\text { RO }\end{array}$ & $\begin{array}{c}\text { Ratio of AVE of } \\
\text { RST }\end{array}$ & $\begin{array}{c}\text { Ratio of AVE of } \\
\text { RSA }\end{array}$ & $\begin{array}{c}\text { Ratio of AVE of } \\
\text { TS }\end{array}$ \\
\hline relative to $r^{2}$ with RO & & 1.231 & 4.258 & 4.453 \\
\hline relative to $r^{2}$ with RST & 1.031 & & 3.637 & 1.604 \\
\hline relative to $r^{2}$ with RSA & 3.341 & 3.408 & & 3.326 \\
\hline relative to $r^{2}$ with TS & 4.086 & 1.758 & 3.890 & \\
\hline
\end{tabular}

A structural equation measurement model was constructed with four factors and regression model with Training satisfaction and Role overload predicting Role stress. No significant regression relationship with Role Satisfaction was established (Figure 2).

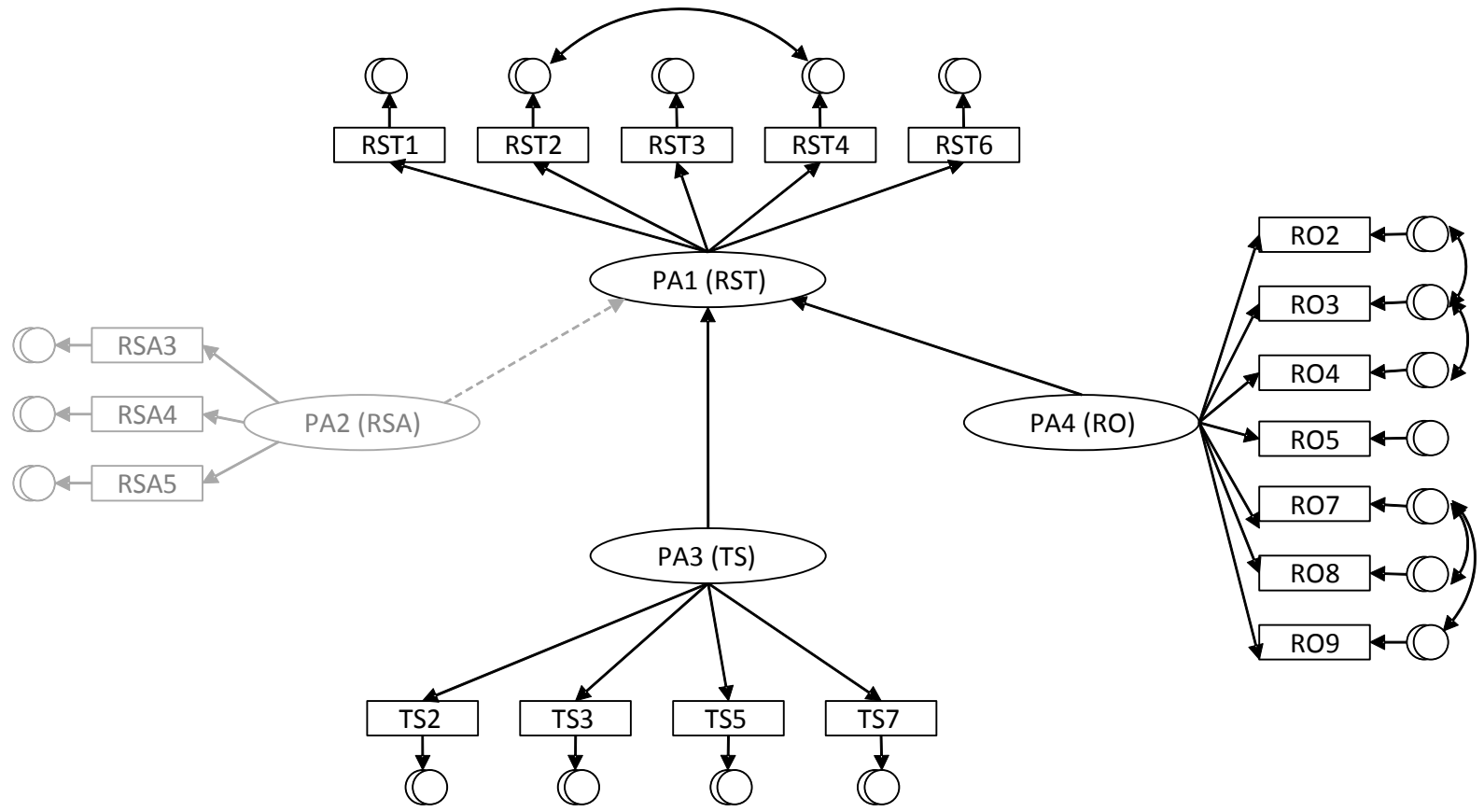

Key: RSA = Role Satisfaction; RST = Role Stress; RO = Role Overload; TS = Training Satisfaction

Figure 2: Structural equation model. Measurement model with four factors and regression model with TS and RO predicting RST

Structural equation model. Measurement model with four factors and regression model with Training satisfaction and Role Overload and control variables predicting Role stress. No significant regression relationship with Role satisfaction was established. 
Table 2: Regression coefficients for the structural equation model of Figure 2

\begin{tabular}{|l|l|l|l|l|}
\hline & $\boldsymbol{\beta}$ & Std. Err & $\boldsymbol{Z}$ & p-value \\
\hline TS & -0.229 & 0.066 & -3.459 & 0.001 \\
\hline RO & 0.638 & 0.134 & 4.772 & 0.000 \\
\hline Residence & 0.000 & 0.008 & 0.002 & 0.998 \\
\hline Gender & 0.080 & 0.101 & 0.791 & 0.429 \\
\hline Age & 0.011 & 0.040 & 0.268 & 0.788 \\
\hline Year of study & 0.055 & 0.072 & 0.755 & 0.450 \\
\hline Residence Tier & 0.076 & 0.121 & 0.630 & 0.529 \\
\hline Leadership role & 0.000 & 13.710 & 0.000 & 1.000 \\
\hline Residence by Gender & -0.025 & 0.067 & -0.37 & 0.711 \\
\hline Race & 0.003 & 0.040 & 0.072 & 0.942 \\
\hline
\end{tabular}

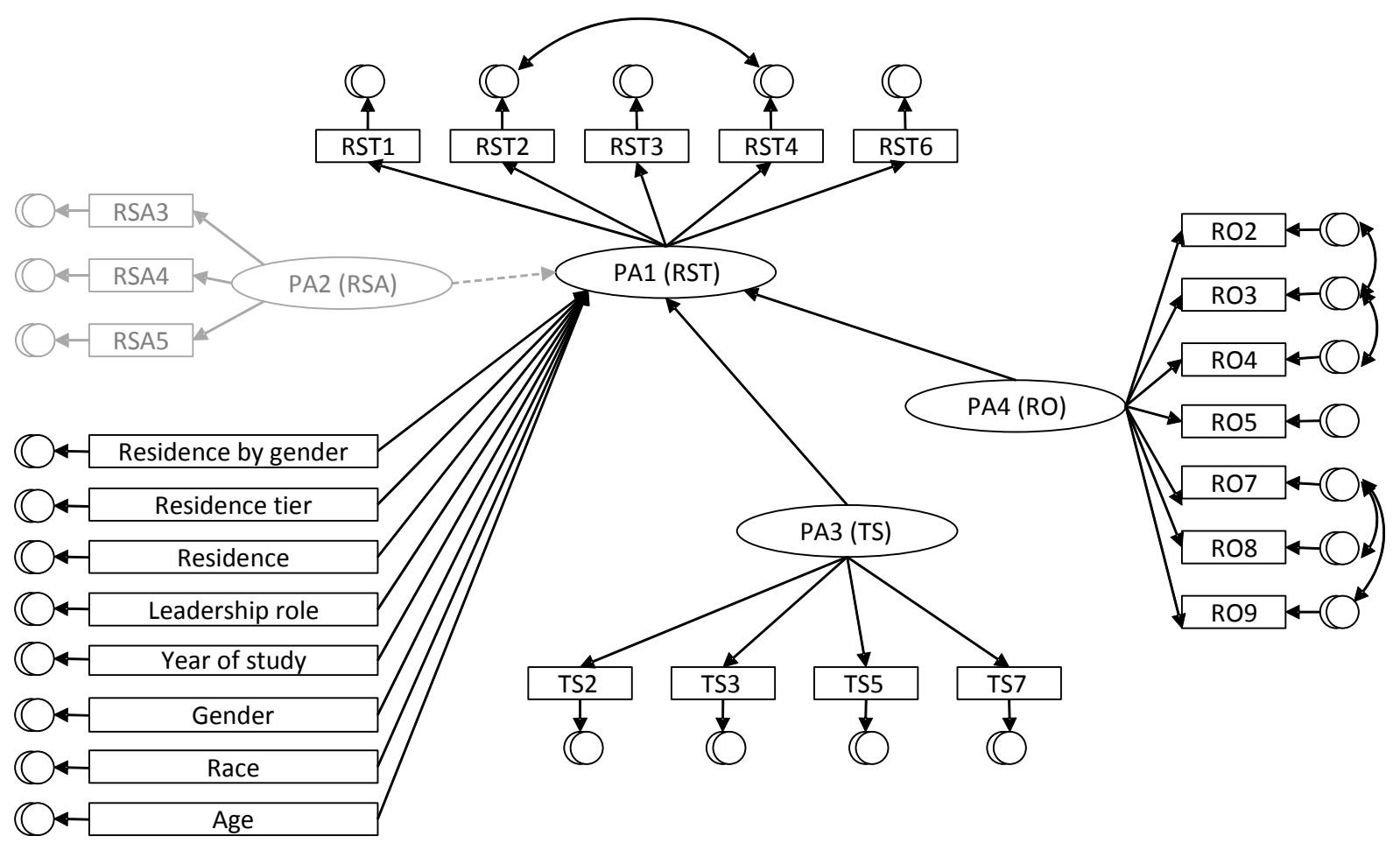

Key: RSA = Role Satisfaction; RST $=$ Role Stress; RO = Role Overload; $\mathrm{TS}=$ Training Satisfaction

Figure 3: Structural equation model. Measurement model with four factors and regression model with TS and RO and control variables predicting RST

\section{DISCUSSION}

The study of stress amongst student leaders in tertiary institution residences has mostly been investigated in developed countries, and reported that stress associated with student leadership roles leads to negative academic outcomes. The aim of this study was to gain insight into the 
perceptions of student leaders regarding role overload, role stress, role satisfaction and utility of training in the South African tertiary environment. Research examining student leaders' perceptions of stress and the related outcomes may help tertiary institutions implement student friendly leadership programmes that foster self-efficacy and civic responsibility amongst student leaders.

\section{Psychometric quality of measures}

There are no known research studies in the South African tertiary environment that address stress among student leaders. Previous measures, developed in contexts dissimilar to the local environment, were used. The scales used appear to be robust for this study sample. Each of the four variables reported reliable values of between 0.76 and 0.86 , which are acceptable according to Pallant (2005). From the findings of this study it can be concluded that the scales used to measure role overload, role satisfaction, role stress and training were reliable and consistent with previous studies.

\section{Role overload}

Student leadership roles are known to be stressful due to the multiple role requirements that student leaders are required to fulfil. This study shows that role overload affects role stress directly, as well as creating role dissatisfaction for the sample. The study findings confirmed the previously reported duplicity of role overload, which has two dimensions, both of which were positively related to role stress. It was also found that student leaders' perception of role stress and role overload were negatively related to role satisfaction, while their perception of training utility was positively related to role overload. Although results showed that training utility did not inhibit the relationship between role overload and role stress, training was found to have a negative relation to role overload and role stress.

Findings from this study indicate the multidimensional aspect of role overload, encompassing both quantitative and qualitative role overload. This finding is supported by (Ross and Altmaier 2000), who included both dimensions when referring to role overload in an organisational context. The inclusion of qualitative role overload was also supported by Gilbert, De Winne and Sels (2011), who found that inadequate job-related competencies due to lack of training were a source of role overload. For role overload among residence student leaders, this result shows that role overload occurs when student leaders perceive themselves to possess an excessive volume of work, and simultaneously perceive that work as being complex, therefore confirming the need for training to enable them to cope with the complexity of the issues with 
which they deal.

The reported positive correlation between role overload and role stress is consistent with results of a study done among a sample of American student leaders (Powers 2003) and salespeople (Jaramillo et al. 2011). Qualitative role overload was reported to be positively related to role stress, which is in line with the Demands and Ability Fit Model (French et al. 1982). This finding shows that student leaders who perceive themselves as not possessing adequate resources (time and competencies) needed to fulfil job tasks, will experience higher levels of role stress. As suggested by Buunk et al. (1998), this result indicates that both dimensions of role overload need to be considered as an important source of role stress, in addition to the commonly cited antecedents of role stress (Chang, Hancock, Johnson, Daly and Jackson 2003). This finding emphasises that tertiary institutions using SLs should monitor the workload imposed and complexity of demands made on the SLs, in order to ensure that role stress is minimised. This is important because high levels of role stress have been linked to a number of negative outcomes (Buunk et al. 1998).

\section{Role Satisfaction}

Findings from this study showed that student leaders' perceived role overload and role stress were negatively correlated to role satisfaction, which is consistent with recent studies conducted by Singh and Dubey (2011). These findings indicate that when SLs feel overloaded and stressed, there will be a negative implication for their role satisfaction and consequently their leadership role. Where SLs are unsatisfied, they have been reported to become apathetic about their role and exhibit low performance levels (Casey 2009). This is detrimental to residence life, since underperforming student leaders may create an unpleasant living environment for their peers, overlook infringements of rules, and even break these rules themselves (Casey 2009). It is important to manage stress levels in order to ensure an effective SL tier, and thus a comfortable living environment for students accommodated in residence halls.

The positive perception of training reported in this study has been cited to lead to higher role satisfaction (Schmidt 2007). This result is also supported by Kristof-Brown, Zimmerman and Johnson (2005), who found that training enhances an individual's competencies to fit job requirements better, which leads to greater role satisfaction and work performance. This finding suggests that training can be recommended as a strategy to enhance role satisfaction When demographic variables were taken into account, it was found that student leaders' perception of role stress was the strongest predictor of role satisfaction among the respondent sample, followed by training utility, and then by qualitative role overload. This result implies that role 
stress is a major threat to role satisfaction. Although training may be an effective strategy to ensure student leader satisfaction, high stress levels may offset its benefits. This emphasizes that universities need to manage student leader stress, in addition to providing beneficial training programmes, in order to keep student leaders satisfied.

\section{Training, Role Overload and Role Stress}

The current findings indicated that student leaders' perception of training utility did not inhibit the relationship between role overload and role stress. This is inconsistent with the Job Demands-Resources model (Demerouti, Bakker, Nachreiner and Schaufeli 2001), on which it is based. A reason for this varying result may be due to the fact that in the current study, training was not defined in accordance with its definition in the Job Demands-Resources model. According to the Job Demands-Resources model, training only moderates the relationship between role overload and role stress when individuals objectively improve their skills (Demerouti et al. 2001). One cannot assume that there is an actual increase in competencies merely because an individual perceives training to be positive. The current study measured SLs' attitude towards training utility, as opposed to their objective increase in competency through training (the Job Demands-Resources model's training definition), which may have skewed the current study's results. Therefore, the current study's error in measuring training may be suggested as a reason for its insignificant result. Future research should consider measuring training outcomes objectively as opposed to subjectively.

This finding is consistent with Kim, Knight and Crustsinger $(2009,549)$ who reported that trainees experienced lower quantitative and qualitative role overload and role stress when the training they received enhanced job-specific skills. For the current context, this shows that when residence student leaders perceive that training equips them better for their leadership roles, they also perceive themselves as coping more readily with time-based and complex demands, and they perceive situations as less stressful. Therefore, the importance of adopting satisfactory training as a strategy in order to maintain low levels of role stress is emphasized.

This study provides a South African-based student leader investigation of the relationship between role overload, role stress and training. Earlier research examining student leaders' stress, role satisfaction and role overload have been conducted mostly in developed countries with socioeconomic factors that differ from those in South Africa (Casey 2009; Dodge 1990; Onoffrietti 2000; Powers 2003). Despite research conducted in the work environment, that shows the negative relationship between work overload, stress and job satisfaction, research investigating the relationship between role overload, role satisfaction, training and 
development, and stress in the local tertiary environment, and specifically among student leaders, is lacking.

In this regard, the current study makes a unique contribution by explaining the perceptions of student leaders with regard to role overload, role satisfaction, training and development, and role stress. These findings are important because tertiary institutions are increasingly developing and implementing student leadership roles that are assumed to contribute to graduate attributes as well as civic responsibility.

\section{Limitations}

The cross-sectional timeframe of the study presents a limitation in the sense that the stability of SL perceptions over time cannot be examined. A longitudinal design would have been preferred, especially when measuring training as an intervention; however, such a study was not feasible due to the transitional nature of the sample population. The use of self-report questionnaires and worker-developed scales adapted for a sample of residence student leaders possibly resulted in a common method bias. Future studies should consider a random sampling approach, drawing from several institutions, to allow for generalization of findings. A qualitative approach would allow for in-depth investigation of nuances of stress and role satisfaction experienced by student leaders.

\section{CONCLUSION}

The main contribution of this study establishes that both role overload and role stress pose a threat to SL role satisfaction, and that training is a strategy that can be adopted to mitigate this threat. This study indicates that training needs to be perceived as beneficial by SLs in order for it to be an effective strategy for ensuring role satisfaction and reduced work overload. In addition to providing satisfactory training, universities need to ensure the effective management of student leaders' stress levels.

\section{ACKNOWLEDGEMENT}

This research was supported by a grant from the Deputy Vice Chancellor: Student Affairs, Professor Crain Soudien and Professor Anwar Mall (2015) at the University of Cape Town. The research was conducted independently, views expressed do not represent the opinions of the University of Cape Town. No conflict of interest exists for the authors. 


\section{REFERENCES}

Buunk, B. P., J. de Jonge, J. F. Ybema and C. J. de Wolff. 1998. Psychosocial aspects of occupational stress. In Work Psychology, ed. P. J. Drenth, H. Thierry and C. J. de Wolff, 145-182. London: Psychology Press Ltd.

Casey, J. L. 2009. Determinants of resident assistant job satisfaction in privatized university housing. Mississippi: The University of Southern Mississippi.

Chang, E. M., K. M. Hancock, A. Johnson, J. Daly and D. Jackson. 2003. Role stress in nurses: Review of related factors and strategies for moving forward. Nurse Health Science 7(1): 57-65.

Curtis, S. 2007. Students' perception of term time employment. Education and training 49(5): 380-390.

Demerouti, E., A. B. Bakker, F. Nachreiner, and W. P. Schaufeli. 2001. The job demands resources model of burnout. Journal of Applied Psychology 86(3): 449-512.

Dodge, S. 1990. The demanding job of resident assistant: Has it grown too big for students? The Chronicle of Higher Education February 21: 39-41.

Ford, J. K. and R. A. Noe. 1987. Self-assessed training needs: The effects of attitudes toward training, managerial level, and function. Personnel Psychology 40(1): 39-53.

French, J. R., R. D. Caplan and R.V. Harrison. 1982. Mechanisms of job stress and strain. Chichester: Wiley \& Sons.

Gilbert, C., S. De Winne and L. Sels. 2011. Antecedents of front-line managers' perceptions of HR role stressors. Personnel Review 40(5): 549-569.

Gilboa, S., A. Shimon, Y. Fried and C. Cooper. 2008. A meta-analysis of work demand stressors and job performance: Examining main and moderating effects. Personnel Psychology 61: 227-271.

Janssen, O. 2001. Fairness perceptions as a moderator in the curvilinear relationships between job demands and job performance and job satisfaction. Academy of Management Journal 44(5): 10391050.

Jaramillo, F., J. P. Mulki and J. S. Boles. 2011. Workplace stressors, job attitudes and job behaviour: Is interpersonal conflict the missing link? The Journal of Personal Selling and Sales Management 31(3): 339-356.

Jones, E., L. Chonko, D. Rangarajan and J. Roberts. 2007. The role of overload on job attitudes, turnover intentions, and salesperson performance. Journal of Business Research 60(7): 663-671.

Kezar, A. and D. Moriarty. 2000. Expanding our understanding of student leadership development: A study exploring gender and ethnic identity. Journal of College Student Development 41(1): 5569.

Kim, H., D. K. Knight and C. Crustsinger. 2009. Generation Y employees' retail work experience: The mediating effect of job characteristics. Journal of Business Research 62(5): 548-556.

Kristof-Brown, A. L., R. D. Zimmerman and E. C. Johnson. 2005. Consequences of individuals' fit at work: A meta-analysis of person-job, person-organisation, person-group and person-supervisor fit. Personnel Psychology 58(2): 281-342.

Onoffrietti, J. M. 2000. Resident assistant stress, job satisfaction and persistence. Boston: Boston College.

Pallant, J. 2005. SPSS survival manual: A step by step guide to data analysis using SPSS for Windows (Version 12). Crows Nest: Allen and Unwin.

Paoline III, E. A., E. G. Lambert and L. N. Hogan. 2006. A calm and happy keeper of the keys: The impact of ACA views, relations with co-workers, and policy views on the job stress and job satisfaction of correctional staff. The Prison Journal 86(2): 182-205.

Powers, K. 2003. The effect of role strain and social isolation among resident assistants. Wise: The University of Virginia's College.

R Core Team. 2015. R: A language and environment for statistical computing. Vienna: R Foundation for Statistical Computing. http://www. R-project.org. 
Revelle, W. 2015. psych: Procedures for Personality and Psychological Research. Evanston: Northwestern University. http://CRAN.R-project.org/package=psych Version = 1.5.1.

Robbins, S. P., T. A. Judge, A. Odendaal and G. Roodt. 2009. Organisational Behaviour: Global and Southern South African Perspectives. Cape Town: Prentice Hall.

Ross, R. R. and E. M. Altmaier. 2000. Intervention in occupational stress. London: Sage Publications Ltd.

Rosseel, Y. 2012. lavaan: An R Package for Structural Equation Modeling. Journal of Statistical Software 48(2): 1-36. http://www.jstatsoft.org/v48/i02/

Schmidt, S. W. 2007. The relationship between satisfaction with workplace training and overall job satisfaction. Human Resource Development Quarterly 18(4): 481-498.

Singh, A. P. and A. K. Dubey. 2011. Role of stress and locus of control in job satisfaction among middle managers. The IUP Journal of Organisational Behavior X(1): 42-56.

Triplett, R., J. L. Mullings and K. E. Scarborough. 1999. Examining the effect of work-home conflict on work-related stress among correctional officers. Journal of Criminal Justice 27(4): 371-385. 